\title{
Young parents' views and experiences of interactions with health professionals
}

\author{
Claire Norman, ${ }^{1,2}$ Suzanne Moffatt, ${ }^{3}$ Judith Rankin ${ }^{4}$
}

\begin{abstract}
${ }^{1}$ Foundation Doctor, Institute of Health \& Society, Newcastle University, Newcastle upon Tyne, UK

${ }^{2}$ Foundation Doctor, Royal Alexandra Hospital, Paisley, UK ${ }^{3}$ Senior Lecturer in Sociology of Health, Institute of Health \& Society, Newcastle University, Newcastle upon Tyne, UK ${ }^{4}$ Professor of Maternal \& Perinatal Epidemiology, Institute of Health \& Society, Newcastle University, Newcastle upon Tyne, UK
\end{abstract}

\section{Correspondence to}

Dr Claire Norman, Institute of Health \& Society, Newcastle University, Baddiley-Clark Building, Richardson Road, Newcastle upon Tyne NE2 4AX, UK; Clairenorman90@gmail.com

Received 8 February 2016 Revised 25 April 2016 Accepted 16 May 2016

\section{SLinked}

- http://dx.doi.org/10.1136/ jprhc-2016-101536

\section{CrossMark}

To cite: Norman C,

Moffatt S, Rankin J. J Fam

Plann Reprod Health Care

2016:42:179-185.

\section{ABSTRACT}

Background Although teenage pregnancy levels are declining, the North East of England still has the highest rate of young parenthood (age $<18$ years) in the UK. Young parents and their children often face many health and social problems, requiring interactions with a wide range of health professionals, such as midwives, doctors and health visitors.

Aim This qualitative interview study aimed to explore young parents' views and experiences of interactions with health professionals.

Methods Young mothers and fathers $(n=10)$ were recruited from youth groups and Sure Start parenting classes in Newcastle upon Tyne during the period April-June 2013. They took part in one-to-one or small group semi-structured interviews regarding their experiences of interacting with health professionals about their own health and that of their child. The interviews were transcribed and analysed using thematic content analysis.

Results Emergent themes included: beliefs about children's health; proving oneself as a parent; and positives of parenting. All the participants distinguished between being a 'firsttime parent, not just a young parent' and all, to varying degrees, challenged the authority and judgement of medical and nursing practitioners with regard to their children's health.

Conclusions The findings of this study highlight the need for health professionals to be particularly aware of the sensitivities arising from the power imbalances perceived by young parents of ill children. This can be achieved by following communication skills frameworks (e.g. the Calgary-Cambridge framework) that emphasise the importance of techniques such as active listening and building rapport.

\section{INTRODUCTION}

Under-18 conception rates are one of the indicators for 'Health improvement' in

\section{Key message points}

This study highlights a need for:

- Better health education for young people and parents with thorough explanations at the point of service use.

- Increased availability of services and more services for parents aged 18-24 years.

- Non-judgemental attitudes from all health professionals.

the Public Health Outcomes Framework for England 2013-2016, ${ }^{1}$ indicating the importance placed on teenage pregnancy and its consequences for health and wellbeing. Although under-18 conception rates are currently at the lowest levels in England and Wales since records began in 1969, the North East of England continues to have the highest rates in the country: 30.6 conceptions per $100015-$ 17-year-olds compared to the England and Wales average of 24.3 per $1000 .^{2}$

Young mothers (typically classified in studies as those aged $<19$ years at the time of birth, although other age categories can be used) are at an increased risk of postnatal depression, ${ }^{3}$ obesity ${ }^{4}$ and death due to violence or assault. ${ }^{5}$ Their children are at increased risk of being born pre-term and dying within the first 28 days of life. ${ }^{6}$ Importantly, socioeconomic factors are also likely to impact on these outcomes as deprivation is considered both a consequence and a cause of teenage pregnancy.

Existing literature on young parents of children with disabilities' interactions with healthcare professionals has found that parents often feel judged by the professionals and that their opinions are 
perceived as invalid. ${ }^{8}$ Tensions can exist between professionals and parents of all ages regarding who knows best for the child and there may be a dichotomy between wanting to seek help promptly but also not wanting to 'bother' the doctor, making it difficult for parents to take the action perceived as correct. ${ }^{9}$ Like most health service users, young people value confidentiality, empathy and thorough explanations from their healthcare professionals ${ }^{10}$ and they do not want to be patronised or judged. ${ }^{11}$ As the quality of patient-practitioner interaction is known to impact on levels of adherence to treatment ${ }^{12}$ and health outcome, ${ }^{13}$ it is important that these interactions are of a high standard. Communication frameworks such as the Calgary-Cambridge framework are often used as a gold standard for consultations. ${ }^{14}$

The aim of this study was to explore young parents' views and experiences of interactions with healthcare professionals. Despite the fact that young parents are already known to be a vulnerable group with whom good communication is key to positive interaction, this study highlights aspects of care that could still be improved.

\section{METHODS}

This research used qualitative research methods employing semi-structured interviews. Ethical approval was obtained from Newcastle University's Faculty of Medical Sciences Research Ethics Committee (Ref: 00627/2013).

\section{Sample and data collection}

Mothers and fathers who were aged 18-24 years at the time of interview, but who had had their first child under the age of 20 years, were eligible for inclusion in the study. Participants were recruited from Sure Start groups [NB. Sure Start children's centres are a government-led initiative that aim to provide high-quality education and childcare support for preschool-aged children.], ${ }^{15}$ a voluntary teenage pregnancy service and local independent youth groups in Newcastle upon Tyne during the period April-June 2013. Given that this population is challenging to recruit, some flexibility on participant characteristics was required. One participant was 24 years old at the time of his child's birth but as he was attending a 'Young Dad's' group, his experiences were still felt to be relevant; likewise a mother who was 20 years old when she gave birth but identified herself as being a young parent was also included. Participants were interviewed alone or in pairs of friends at a location that the young parents were comfortable with and where their children could be looked after during the interview. A request was made to audio record the interview, most participants $(n=8 / 10)$ gave consent. The two participants who refused to be recorded agreed to contemporaneous notes being taken. Interviews lasted 20-45 minutes; a topic guide was used which covered experiences of good and bad consultations, experiences regarding seeking help for themselves and for their children, and any issues they felt were particularly relevant to young parents.

\section{Data analysis}

Interviews were transcribed in full, checked for accuracy and extensively re-read by $\mathrm{CN}$, with input from SM and JR. Thematic content analysis ${ }^{16}$ was used whereby themes were derived from the interview data in its transcript form, using line-by-line analysis. A coding frame was drawn up by all authors, grounded in the data from the first three transcripts. The initial 146 explanatory and analytical codes deduced were grouped into a framework of subthemes and overarching themes (Figure 1) and applied to the rest of the transcripts. NVivo software was used to code and manage the data, and constant comparison of the transcripts allowed concepts to emerge and be mapped to the framework. Deviant case analysis,

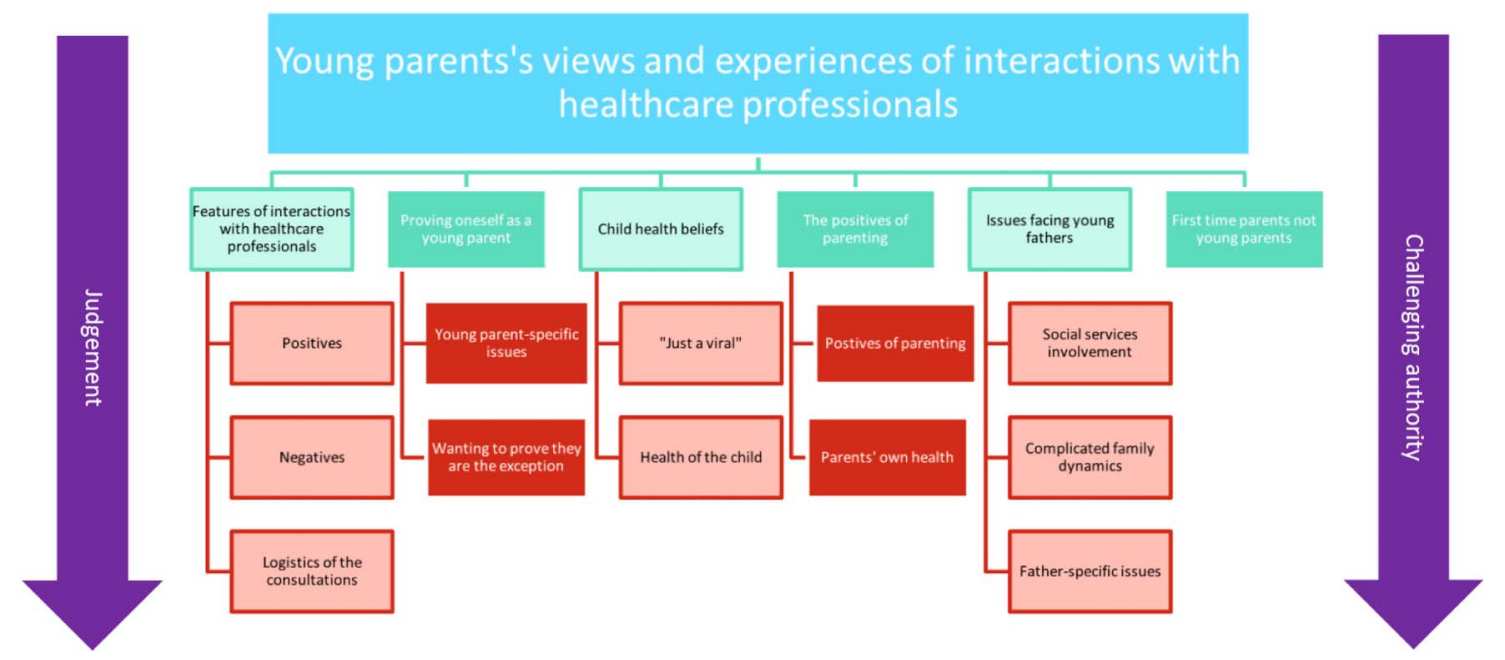

Figure 1 Themes, subthemes and over-arching themes. 
where we sought out and examined narratives which modified or contradicted the analysis, was used to enhance validity. ${ }^{17} 18$

\section{RESULTS}

\section{Participant characteristics}

Seven women and three men aged 18-24 years (none in a partnership) were interviewed (Table 1). Seven participants lived in socio-economically deprived areas of Newcastle (as derived from their residential postcode at the time of interview), one was a university student, one lived in a relatively affluent area and postcode data was not obtained from the final participant. Pseudonyms are used throughout and illustrative quotes are presented.

\section{Research findings}

A total of 146 initial codes were mapped to 12 subthemes and six overarching descriptive themes (Figure 1). Two overarching themes of 'judgement' and 'challenging authority' were also identified as being present throughout all interviews. The themes deemed most relevant to improving practice are explored below. Young father-specific issues are not included as we felt their views have been extensively researched by Ross et al. ${ }^{19}$

\section{Features of interactions with healthcare professionals}

Difficulties in accessing healthcare was a common theme throughout the interviews. Young parents were frustrated by difficulties in obtaining appointments to see their general practitioner (GP) or health visitor. One mother attended a GP surgery with a drop-in clinic for babies and felt this service should be more widely available. Conversely, a number of the other parents lived in an area with a drop-in centre that would not see children under the age of 2 years, resulting in parents inappropriately using emergency appointment slots at their GP surgery or attending a hospital accident and emergency department.

Regarding the consultation itself, positive attributes and traits included professionals who made it obvious

Table 1 Participant characteristics

\begin{tabular}{lcc}
\hline Characteristic & $\boldsymbol{n}(\%)$ \\
\hline Female & 7 & $(70)$ \\
Male & 3 & $(30)$ \\
White British & $10(100)$ \\
Age (in years) at birth of first child & & \\
$\quad 16-17$ & 6 & $(60)$ \\
$18-19$ & 2 & $(20)$ \\
$\quad 20+$ & 2 & $(20)$ \\
Employed or in education & 5 & $(50)$ \\
One child & 8 & $(80)$ \\
Lives in lowest index of multiple deprivation (IMD) quintile & 7 & $(70)$ \\
Living with child's other parent & 3 & $(30)$ \\
\hline
\end{tabular}

that they were listening and non-judgemental, as well as those who were perceived as competent and interacted well with children. Negative features were the converse of these: professionals who were rushed, condescending or were perceived to make incorrect diagnoses and management plans. Some participants mentioned that they felt like most health professionals were in a different class to them, and although this generally led to a poorer relationship it could be beneficial if the professional acted as an advocate.

"At the [social services] meeting [midwife] was saying some of the things that I was trying to get across ... and with her being a professional, obviously people listen to professionals, unlike me being a nobody." [Rob, 24 years old]

Child health beliefs and proving oneself as a young parent

Disagreements between parents and health professionals regarding the health of a child was a common cause of negative feeling. Participants felt that they (or their own parents) knew more about bringing up children than 'pushy' health visitors. They gave examples of times when they had intuitively known something was wrong with their child but were told it was "just a viral [virus]". Dismissal of concerns with the explanation that symptoms were due to a viral illness was a common complaint; participants avoided seeking help because they were never satisfied with the outcome of the consultation. One mother was keen to point out an occasion when her GP had dismissed her concerns and the child had subsequently needed hospital investigations.

"He telt [told] me that my baby was fine when she was in hospital with suspected meningitis so why should I listen to him ... he's useless.” [Kay, 20 years old]

The participants were determined to prove themselves as good parents. Mothers felt that their age led to being 'looked down on' by health professionals and members of the public.

"The doctors look at you like you're just young and stupid and they know everything and you don't know anything." [Lisa, 21 years old]

Interestingly this was not a feeling shared by the young fathers, who denied feeling judged.

Although insistent that they should not be treated differently because of their age, some participants felt that they would benefit from extra support. They typically had positive experiences of parenting classes such as those run by Sure Start, although stressed that attendance at these should be voluntary not mandatory - another indication that autonomy and selfdetermination is very important to young parents.

The participants seemed keen to show that they were different from the stereotypical perception of young parents. They themselves looked down upon others they knew who had been significantly younger 
when becoming pregnant or whom they felt had only started a family for financial gain. This lack of solidarity or 'othering' could be viewed as an attempt to distance themselves from the negative stereotypes directed at teenage parents and is commonly found among already stigmatised groups. ${ }^{20}$

"Obviously you do get teenagers doing things like just to get a house ... cos obviously there is a lot of people that do that, so they just judge all teenage mums." [Lisa, 21 years old]

\section{Judgement and challenging authority}

Judgement and 'challenging authority' were two overarching themes present throughout all interviews. Poor relationships between participant and practitioner were often fuelled by disagreement over who knew best regarding the child's healthcare. The young parents saw themselves as experts regarding their child; a position that most of them were seldom in and as such reluctant to let go of, particularly to a health professional whom they perceived to be disinterested and from a different social background. They wanted to challenge the paternalistic patient-practitioner relationship.

Not all professionals were criticised, however. Midwives were generally viewed favourably by the young parents, compared to health visitors or GPs. This may have been due to the timing of their involvement; midwives being present before and immediately after the birth of the child, giving advice and encouragement. A perinatal psychiatric nurse was particularly praised.

\section{"I just got like a really good bond with her, really good ... it didn't feel like she was judging us or anything like that." [Lisa, 21 years old]}

This compared unfavourably with doctors who were sought when something was going wrong and health visitors who were perceived as 'checking up' on the child and parent.

"[Health visitor] thinks that as a young mum that I couldn't do anything. Like I was stupid.” [Kayleigh, 20 years old]

In difficult or stressful scenarios there may have been more chance for perceived criticism of parenting abilities.

Young parents felt they were being judged and criticised for being a parent - "everyone just slates you for being a mum at 16", said Alyssa, aged 20 years. This judgement was felt to be linked to age and perceptions of intelligence.

"I guess if you're younger, you're less educated and they just assume you don't know as much." [Rachel, 24 years old]

Feeling looked down upon was commonly experienced, and consequently young parents were reluctant to engage with health professionals. Even midwives lost favour if they were 'bossy' or 'pushy,' highlighting again the young parents' need to feel in control of their situation and have their views taken seriously.

\section{DISCUSSION}

This study confirms what is already known about what young parents want from a health practitioner; professionals who listen, are non-judgemental and easy to contact. ${ }^{8} 1011$ These are aspects of holistic, patient-centred care that all professionals should be providing. ${ }^{21}$ However, this study also found that young parents' feel the need to prove their worth as caregivers, often manifesting in a tendency to challenge the authority of health professionals. This reflects Brady et al.'s ${ }^{22}$ work highlighting the importance of young parents feeling in control when accessing healthcare. We suggest that this urgency to prove their parental knowledge and abilities is a response to the prevailing societal judgement and stigma directed towards young parents. $^{23} 24$ Participants' accounts demonstrated that they were angered and dismayed when their concerns were dismissed. They were faced with a quandary similar to the participants in Neil et al.'s 2013 study; either be put off seeking help and be regarded as a bad parent or attend and be subsequently criticised for wasting time with a viral illness. In contrast to studies from the $1970 \mathrm{~s},{ }^{25}{ }^{26}$ our study participants showed no indication of being 'in awe' of the health professionals. They saw instant access to healthcare as their right, and some participants made scathing judgements regarding health professionals' competence.

Particularly negative experiences could prevent the parents interviewed consulting with a GP or health visitor. Instead, parents would go straight to the accident and emergency department at the hospital, which is far from ideal when UK secondary care services are already stretched. ${ }^{27}$ As patient satisfaction and health outcome is linked to the quality of patient-practitioner relationship, ${ }^{13}$ the poor health status of young parents and their children may be linked to their perceived poor relationship with various healthcare professionals.

The young people in this study spoke highly of their local Sure Start groups, which provide practical help and advice as well as an opportunity to make friends who were sharing similar experiences. Although it was felt that attendance at these classes should be voluntary not mandatory, they were obviously a valued asset. Unfortunately, services such as these are subject to funding cuts due to austerity -driven public sector budget reductions, which are disproportionately hitting the poorest areas with the worst health outcomes hardest. ${ }^{28}$ Worryingly, further cuts to public spending and welfare will result from the latest UK government budget. ${ }^{29}$ Suggestions for improvement included better advertising of existing services by GPs 
and midwives and more services aimed at parents aged around 18-24 years, who felt that their needs were neglected in favour of very young mothers $(<16$ years) or older, professional women.

The strengths of this study lie in the acquisition of primary data from a group of young people who are challenging to recruit into studies. Early engagement with stakeholders ensured that the subject topics were relevant and acceptable, which was helped by the fact that the primary researcher was of a similar age to the participants. Thematic content analysis provided a thorough and rigorous exploration of the data.

Limitations of this study included that participants were normally attendees of Sure Start or similar groups, and as they had already shown a willingness to engage with such services, their views may have differed from those of less engaged young people. Some participants $(n=4)$ were aware that the interviewer $(\mathrm{CN})$ was a medical student, which may have influenced their answers. The older participants may have had different experiences and their views may not be as applicable to younger parents.

Ultimately, this research demonstrated the need for better communication skills and mutual respect between young parents and the health professionals who care for them and their children. Many of the grievances aired by participants related to the dismissal of health complaints as trivial. If health professionals had more time to establish what parents' ideas, concerns and expectations were and, if necessary, explain to the parents why they were not recommending further treatment for the child, better understanding and relationships might ensue. Health professionals need to convey the fact that they are taking concerns seriously and that they are actively eliciting and listening to the parents' concerns. Ideally, the formation of a collaborative relationship between parent and practitioner could result in the young parent leaving the consultation feeling reassured about their child's health and also educated about similar complaints in the future, rather than sensing real or enacted criticism. However, the constraints of time in the consultation make this a challenge to achieve.

Adequate 'safety-netting' is required to ensure that a parent knows to bring their child back to the attention of the health services should the health of the child deteriorate. Active listening and safety-netting are now core communication skills that are taught to health professionals using tools such as the CalgaryCambridge framework, but it may be necessary to promote their more widespread use in practice. $^{30}$ Applying experiences of good and bad practice onto the Calgary-Cambridge framework, as shown in Figure 2, demonstrates how the findings of this study could form the basis of further training for health professionals working with this client group. This framework was chosen as an example due to its widespread use in undergraduate and postgraduate medical education. ${ }^{31}$ Positive examples are highlighted with a green box and negative examples are bordered red.

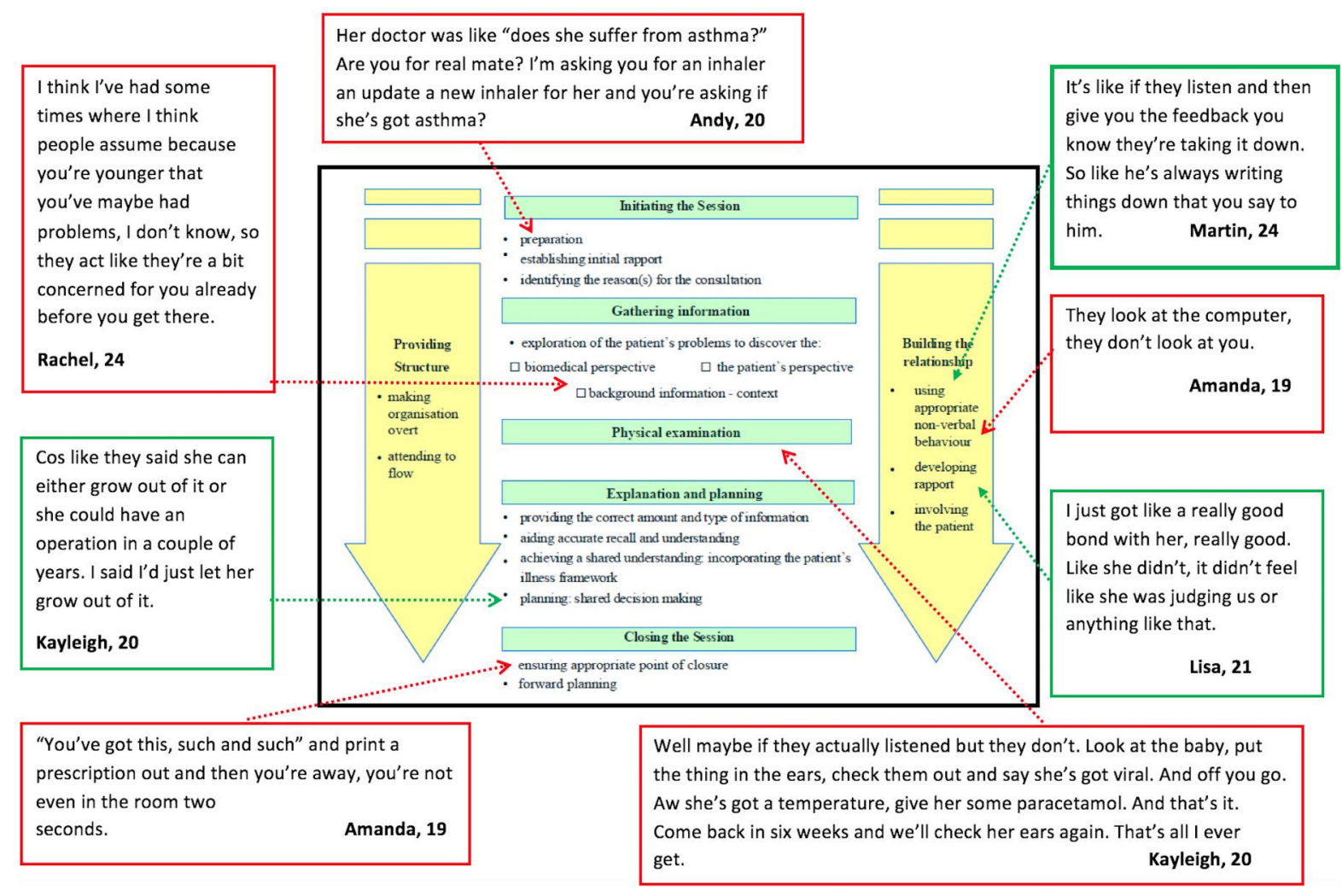

Figure 2 Positive and negative experiences mapped to the Calgary-Cambridge framework. 


\section{REFERENCES}

1 Department of Health. A Public Health Outcomes Framework for England, 2013-2016. London, UK: Department of Health, 2013.

2 Office for National Statistics (ONS). Conceptions in England and Wales: 2013. London, UK: ONS, 2015.

3 Reid V, Meadows-Oliver M. Postpartum depression in adolescent mothers: an integrative review of the literature. J Pediatr Health Care 2007;21:289-298.

4 Lemay CA, Elfenbein DS, Cashman SB, et al. The body mass index of teen mothers and their toddler children. Matern Child Health J 2008;12:112-118.

5 Otterblad Olausson P, Haglund B, Ringbäck Weitoft G, et al. Premature death among teenage mothers. BJOG 2004;111:793-799.

6 Chen X-K, Wen SW, Fleming N, et al. Teenage pregnancy and adverse birth outcomes: a large population based retrospective cohort study. Int J Epidemiol 2007;36:368-373.

7 Swann C, Bowe K, McCormick G, et al. Teenage Pregnancy and Parenthood: A Review of Reviews. London, UK: NHS Health Development Agency, 2003.

8 Lea D. 'You don't know me like that': patterns of disconnect between adolescent mothers of children with disabilities

and their early interventionists. $J$ Early Interv 2006;28:264-282.

9 Neill SJ. Containing acute childhood illness within family life: a substantive grounded theory. J Child Health Care 2010;14:327-344.

10 Freake H, Barley V, Kent G. Adolescents' views of helping professionals: a review of the literature. J Adolesc 2007;30:639-653.

11 Jacobson L, Richardson G, Parry-Langdon N, et al. How do teenagers and primary healthcare providers view each other? An overview of key themes. Br J Gen Pract 2001;51:811-816.

12 Haskard Zolnierek KB, Dimatteo MR. Physician communication and patient adherence to treatment: a meta-analysis. Med Care 2009;47:826-834.

13 Stewart MA. Effective physician-patient communication and health outcomes: a review. CMAJ 1995;152:1423.

14 Kurtz SM, Silverman JD. The Calgary-Cambridge Referenced Observation Guides: an aid to defining the curriculum and organizing the teaching in communication training programmes. Med Educ 1996;30:83-89.

15 Children Schools and Families Committee. Sure Start Children's Centres. London, UK: House of Commons, 2010.

16 Robson C. Thematic coding analysis. In: Real World Research: A Resource for Social Scientists and Practitioner-Researchers. Chichester, UK: John Wiley, 2002:474-489.

17 Glaser BG, Strauss AL. The Discovery of Grounded Theory: Strategies for Qualitative Research. London, UK: Aldine Transaction, 2009.

18 Barbour RS. Checklists for improving rigour in qualitative research: a case of the tail wagging the $\operatorname{dog}$ ? $B M J$ 2001;322:1115-1117.

19 Ross NJ, Church S, Hill M, et al. The perspectives of young men and their teenage partners on maternity and health services during pregnancy and early parenthood. Child Soc 2012;26:304-315.

20 Peacock M, Bissell P, Owen J. Dependency denied: health inequalities in the neo-liberal era. Soc Sci Med 2014;118:173-180.

21 Mead N, Bower P. Patient-centredness: a conceptual framework and review of the empirical literature. Soc Sci Med 2000;51:1087-1110.

22 Brady G, Brown G, Wilson, C, et al. New ways with young mothers - how services can better meet their needs. Midwifery Dig 2008;18:579-581.

23 Mulherin K, Johnstone M. Qualitative accounts of teenage and emerging adult women adjusting to motherhood. J Reprod Infant Psychol 2015;33:388-401.

24 Whitley R, Kirmayer LJ. Perceived stigmatisation of young mothers: an exploratory study of psychological and social experience. Soc Sci Med 2008;66:339-348.

25 Stacey M, Dearden R, Pill R, et al. Practical recommendations. In: Hospitals, Children and Their Families: The Report of a Pilot Study. Abingdon-on-Thames, UK: Routledge \& Kegan Paul, 1970:141-160.

26 Strong PM. Character work and the charity format. In: The Ceremonial Order of the Clinic: Parents, Doctors, and Medical Bureaucracies. Abingdon-on-Thames, UK; Routledge \& Kegan Paul, 1979:41-45.

27 The King's Fund. What's going on in A\&E? The key questions answered. 2015. http://www.kingsfund.org.uk/projects/ urgent-emergency-care/urgent-and-emergency-care-mythbusters [accessed 4 April 2016]. 
28 Whitehead M. Due North Report of the Inquiry on Health Equity for the North. Liverpool and Manchester, UK:

University of Liverpool and Centre for Local Economic Strategies, 2014.

29 HM Treasury and The Right Honourable George Osborne MP. Summer Budget 2015: London, UK: HM Treasury, 2015.
30 Silverman J, Kurtz SM, Draper J. Relating specific issues to core communication skills. In: Skills for Communicating with Patients. Oxford, UK: Radcliffe Publishing, 2005:207-236.

31 Gillard S, Benson J, Silverman J. Teaching and assessment of explanation and planning in medical schools in the United Kingdom: cross sectional questionnaire survey. Med Teach 2009;31:328-331. 